\title{
The critical role of electrochemically activated adsorbates in neutral OER
}

\author{
Longsheng Zhang ${ }^{1 \dagger}$, Haiyang Yuan ${ }^{2 \dagger}$, Liping Wang ${ }^{1}$, Hui Zhang ${ }^{3}$, Yijing Zang ${ }^{3}$, Yao Tian ${ }^{4}$, \\ Yunzhou Wen ${ }^{1}$, Fenglou Ni ${ }^{1}$, Hao Song ${ }^{4}$, Haifeng Wang ${ }^{2^{*}}$, Bo Zhang ${ }^{1^{*}}$ and Huisheng Peng ${ }^{1^{*}}$
}

\begin{abstract}
Developing efficient electrocatalysts for the oxygen evolution reaction (OER) under neutral conditions is important for microbial electrolysis cells (MECs). However, the OER kinetics in neutral electrolytes at present are extremely sluggish, resulting in high overpotentials that greatly limit the energy conversion efficiencies of MECs. Previous studies failed to probe the adsorbates on surface metal sites of catalysts at the atomic scale and elucidate their influence on the catalytic activities, which has impeded the rational design of efficient neutral OER catalysts with optimal surface structures. Here, using in situ transmission electron microscopy (TEM), in situ X-ray photoelectron spectroscopy (XPS) and in situ low-energy ion scattering studies, we have identified, for the first time, that the electrochemically activated adsorbates on surface metal sites play a critical role in boosting the neutral OER activities of Ru-Ir binary oxide $\left(\mathrm{Ru}_{x} \mathrm{Ir}_{y} \mathrm{O}_{2}\right)$ catalysts. The adsorbate-activated $\mathrm{Ru}_{x} \mathrm{Ir}_{y} \mathrm{O}_{2}$ on a glassy carbon electrode achieved a low overpotential of $324 \mathrm{mV}$ at $10 \mathrm{~mA} \mathrm{~cm}{ }^{-2}$ in neutral electrolyte, with a 36-fold improvement in turnover frequency compared with that of $\mathrm{IrO}_{2}$ benchmark. Upon application in an MEC system, the resulting full cell showed a decreased voltage of $1.8 \mathrm{~V}, 200 \mathrm{mV}$ lower than the best value reported to date, facilitating efficient synthesis of poly(3-hydroxybutyrate) from bioelectrochemical $\mathrm{CO}_{2}$ reduction. Density functional theory (DFT) studies revealed that the enhanced OER activity of $\mathrm{Ru}_{x} \mathrm{Ir}_{y} \mathrm{O}_{2}$ catalyst arose from local structural distortion of adjacent adsorbate-covered Ru octa-
\end{abstract}

hedra at the catalyst surface and the consequently decreased adsorption energies of OER intermediates on Ir active center.

Keywords: electrocatalysis, oxygen evolution reaction, adsorbates, neutral electrolytes

\section{INTRODUCTION}

The oxygen evolution reaction (OER) is of prime importance for various renewable energy systems and technologies including water electrolyzers, electrochemical $\mathrm{CO}_{2}$ reduction electrolyzers and microbial electrolysis cells (MECs) [1]. MEC is known as the only technology that can be used for the direct bioelectrochemical reduction of $\mathrm{CO}_{2}$ to high-value-added $\mathrm{C}_{4+}$ chemicals [2]. The microbes in an MEC require a neutral working $\mathrm{pH}$, and necessitate a neutral OER at the counter electrode. Unfortunately, the OER kinetics in neutral electrolytes are more sluggish than those in acidic or alkaline electrolytes, leading to much higher overpotentials [3-8], which greatly limit the electrical-to-chemical energy conversion efficiencies of MECs.

To date, iridium (Ir) oxide is one of the most appropriate OER catalysts, combining its activity and stability, but its potential in neutral media has not yet been fully unfolded [9-12]. It has been theoretically and experimentally found that the adsorption energies of OER intermediates on Ir oxide are too high, and thus, the OER

\footnotetext{
${ }^{1}$ State Key Laboratory of Molecular Engineering of Polymers, Department of Macromolecular Science and Laboratory of Advanced Materials, Fudan University, Shanghai 200438, China

${ }^{2}$ Key Laboratory for Advanced Materials, Key Laboratory for Advanced Materials, Centre for Computational Chemistry and Research Institute of Industrial Catalysis, East China University of Science and Technology, Shanghai 200237, China

${ }^{3}$ State Key Laboratory of Functional Materials for Informatics, Shanghai Institute of Microsystem and Information Technology, Chinese Academy of Sciences, CAS Center for Excellence in Superconducting Electronics, Shanghai 200050, China

${ }^{4}$ Key Laboratory of Systems Bioengineering, School of Chemical Engineering and Technology, SynBio Research Platform, Collaborative Innovation Centre of Chemical Science and Engineering, Tianjin University, Tianjin 300072, China

${ }^{\dagger}$ These authors contributed equally to this work.

* Corresponding authors (emails: hfwang@ecust.edu.cn (Wang H); bozhang@fudan.edu.cn (Zhang B); penghs@fudan.edu.cn (Peng H))
} 
activity can be enhanced by generating $\operatorname{IrO}_{x}(\mathrm{OH})_{y}$ species at the catalyst surface that have decreased adsorption energies of OER intermediates $[13,14]$. Such $\operatorname{IrO}_{x}(\mathrm{OH})_{y}$ species are generated and activated by the adsorbed hydroxyl groups during the OER process $[15,16]$. However, the extremely low concentration of adsorbed hydroxyl groups on the catalyst surface in neutral electrolyte hinders the generation of active $\operatorname{IrO}_{x}(\mathrm{OH})_{y}$ species [17-20], thereby resulting in the low neutral OER activity of Ir oxide catalyst.

Alternatively, recent studies have shown that by incorporating a second metal element as a dopant, the strong interactions between the dual-metal sites can affect the surface structures and further decrease the adsorption energies of OER intermediates on Ir active sites [21-24]. According to bond-order conservation principles, in a dual-metal-site system, stronger adsorption energies of intermediates on adjacent metal sites can enable weaker adsorption energies of the intermediates on center metal sites [25], offering opportunities to tailor the adsorption energies and thereby the OER activity. Ruthenium $(\mathrm{Ru})$ oxide possesses high binding energies of oxygen intermediates [26], which inspires us to use Ru to optimize the adsorption energies of the OER intermediates on the $\mathrm{Ru}$ Ir dual-site surface.

Here, we developed a physical model to explore the OER energetics of Ru-Ir binary oxides, aiming to unravel the influence of adsorbed oxygen species on $\mathrm{Ru}$ and $\mathrm{Ir}$ sites. We synthesized Ru-Ir binary oxide in an atomically homogenous manner, and the obtained catalyst on a glassy carbon electrode achieved a low overpotential of $324 \mathrm{mV}$ at $10 \mathrm{~mA} \mathrm{~cm}^{-2}$ in neutral electrolyte, with a 36fold improvement in turnover frequency (TOF) compared with that of $\mathrm{IrO}_{2}$ benchmark. When the catalyst was used in an MEC system, the resulting full-cell voltage was greatly decreased to $1.8 \mathrm{~V}$, which is $200 \mathrm{mV}$ lower than the best value reported to date $[2,27,28]$, facilitating efficient synthesis of poly(3-hydroxybutyrate) (a biodegradable plastic) from bioelectrochemical $\mathrm{CO}_{2}$ reduction. In situ low-energy ion scattering (LEIS) combined with in situ X-ray photoelectron spectroscopy (XPS) and in situ transmission electron microscopy (TEM) studies have identified, for the first time, that the electrochemically activated OER adsorbates on the surfaces of Ru sites play a critical role in boosting the neutral OER activities of RuIr binary oxide catalysts. Further theoretical studies indicate that the improved OER activity of Ru-Ir binary oxide arises from the structural distortion of adjacent adsorbate-covered $\mathrm{Ru}$ octahedra at the catalyst surface and the consequently decreased adsorption energies of
OER intermediates on the Ir active center.

\section{EXPERIMENTAL SECTION}

\section{Preparation of Ru-Ir binary oxide catalyst}

First, metal salt precursors $\left(0.3 \mathrm{mmol} \mathrm{RuCl} \cdot x \mathrm{H}_{2} \mathrm{O}\right.$ and $\left.0.1 \mathrm{mmol} \mathrm{Na}_{3} \mathrm{IrCl}_{6} \cdot x \mathrm{H}_{2} \mathrm{O}\right)$ were dissolved in $4 \mathrm{~mL} \mathrm{N,N-}$ dimethylformamide (DMF). Then, $0.5 \mathrm{~mL}$ propylene oxide was slowly added dropwise under stirring. The mixed solution was then sealed and aged for $1 \mathrm{~d}$, and black precipitates appeared. Afterwards, the solution and precipitates were transferred into a vial and immersed in acetone for $3 \mathrm{~d}$ before they were collected by centrifugation and washing with acetone for 5 times to remove DMF and propylene oxide. The precipitates were dried in vacuum and then grinded carefully. Finally, the asobtained black powder was placed into a tube furnace and annealed at $400^{\circ} \mathrm{C}$ in air for $2 \mathrm{~h}$ to obtain the Ru-Ir binary oxide catalyst.

\section{Electrochemical measurements}

Electrochemical measurements were performed in a three-electrode system connected to an electrochemical workstation, using $\mathrm{Ag} / \mathrm{AgCl}$ as the reference electrode and platinum foil as the counter electrode. Cyclic voltammetry $(\mathrm{CV})$ measurements at a scan rate of $50 \mathrm{mV} \mathrm{s}^{-1}$ were performed to achieve stable $\mathrm{CV}$ scans in $\mathrm{CO}_{2}{ }^{-}$ saturated $0.5 \mathrm{~mol} \mathrm{~L}^{-1} \mathrm{KHCO}_{3}$ aqueous electrolyte before conducting linear sweep voltammetry (LSV) at a scan rate of $1 \mathrm{mV} \mathrm{s}^{-1}$ for the catalysts. All the potentials were referenced to the reversible hydrogen electrode (RHE). The electrochemically active surface areas of catalysts were calculated based on their electrical double-layer capacitances, the values of which were obtained from CV scans in a narrow non-Faradaic potential window. Specific activities of the catalysts were calculated by normalizing the currents to the electrochemically active surface areas of catalysts. For full details, see the Supplementary information.

\section{RESULTS AND DISCUSSION}

We first assessed the influence of adsorbed oxygen species on the OER energetics on Ru-Ir binary oxide $\left(\mathrm{Ru}_{x} \mathrm{Ir}_{y} \mathrm{O}_{2}\right)$ surface using density functional theory (DFT). Here we proposed a $\mathrm{Ru}_{x} \mathrm{Ir}_{y} \mathrm{O}_{2}$ (110) model that is a uniform solid solution in an effective catalysis range (top two atomic layers), and we altered the $\mathrm{Ru} / \mathrm{Ir}$ atomic ratios in various $\mathrm{Ru}_{x} \mathrm{Ir}_{y} \mathrm{O}_{2}$ models $(x=0,0.25,0.5,0.75$ and $1, y=1-x$; see Fig. S1a). The $\mathrm{Ru}_{0.5} \mathrm{Ir}_{0.5} \mathrm{O}_{2}$ (110) model was used as an example to illustrate different active sites (Fig. 1a-g). The 

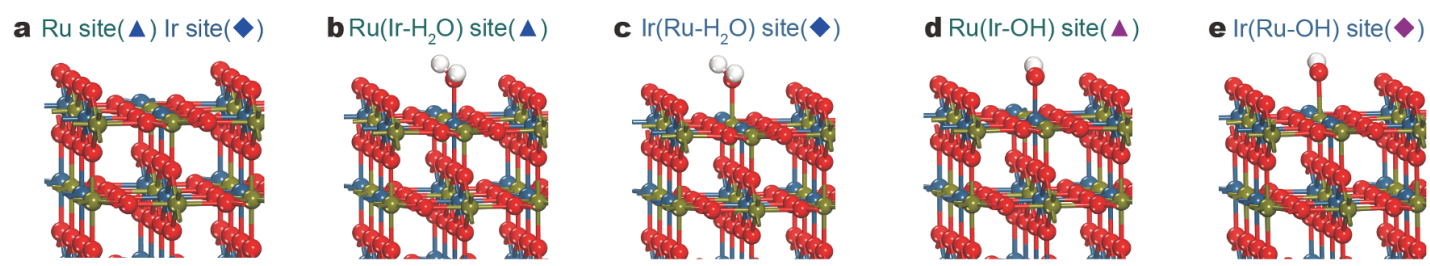

$\mathrm{H}$

$\mathrm{O}$

Pu

Ir

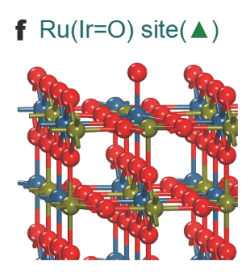

g $\operatorname{Ir}(\mathrm{Ru}=\mathrm{O}) \operatorname{site}(\diamond)$

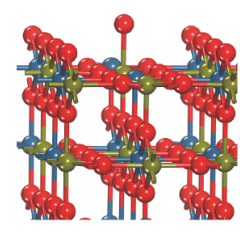

h
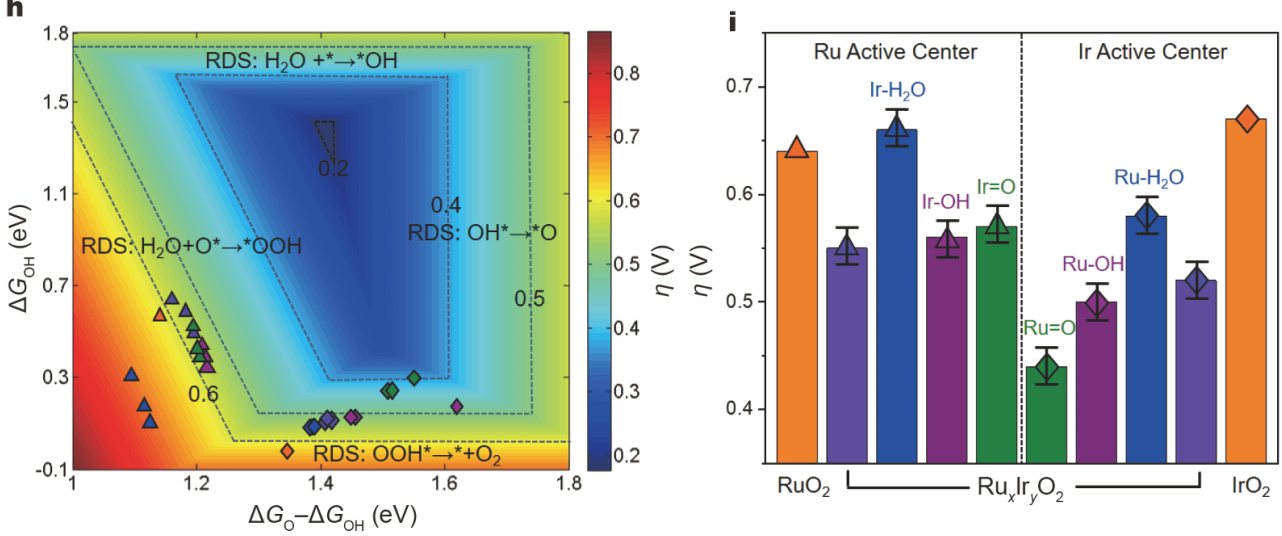

Figure 1 DFT studies of adsorbate-covered $\mathrm{Ru}_{x} \mathrm{Ir}_{y} \mathrm{O}_{2}$ catalysts for OER. (a-g) The active sites on the $\mathrm{Ru}_{x} \mathrm{Ir}_{y} \mathrm{O}_{2}$ (110) model with $x=y=0.5$ as an example: (a) Ru active site (violet " $\Delta$ ") and Ir active site (violet " $\diamond$ ") on a clean $\mathrm{Ru}_{0.5} \mathrm{Ir}_{0.5} \mathrm{O}_{2}$ (110) surface; (b, d, f) Ru active site with adjacent $\operatorname{Ir}-\mathrm{H}_{2} \mathrm{O}$ $\left(\mathrm{Ru}\left(\mathrm{Ir}-\mathrm{H}_{2} \mathrm{O}\right)\right.$, blue " $\Delta$ "), Ir-OH $(\mathrm{Ru}(\mathrm{Ir}-\mathrm{OH})$, purple " $\Delta$ ") and $\mathrm{Ir}=\mathrm{O}(\mathrm{Ru}(\mathrm{Ir}=\mathrm{O})$, olive " $\Delta$ ") species, respectively; (c, e, g) Ir active site with adjacent Ru$\mathrm{H}_{2} \mathrm{O}\left(\operatorname{Ir}\left(\mathrm{Ru}-\mathrm{H}_{2} \mathrm{O}\right)\right.$, blue " $\diamond$ "), $\mathrm{Ru}-\mathrm{OH}(\operatorname{Ir}(\mathrm{Ru}-\mathrm{OH})$, purple " $\diamond$ ") and $\mathrm{Ru}-\mathrm{OH}(\operatorname{Ir}(\mathrm{Ru}=\mathrm{O})$, olive " $\diamond$ ") species, respectively. (h) The OER activity volcano map of overpotentials $(\eta)$ for $\mathrm{Ru}_{x} \mathrm{Ir}_{y} \mathrm{O}_{2}(110)$ as a function of $\Delta G_{\mathrm{O}}-\Delta G_{\mathrm{OH}}$ and $\Delta G_{\mathrm{OH}}$. (i) Summary of overpotentials for the Ir and Ru active sites in (h), where " $\Delta$ " and " $\diamond$ " with different colors correspond to the different kinds of active sites in $\mathrm{Ru}_{x} \mathrm{Ir}_{y} \mathrm{O}_{2}(110)$.

adsorption Gibbs energies $\left(\Delta G_{\mathrm{X}}\right)$ of OER intermediates $\left(\mathrm{OH}^{*}, \mathrm{O}^{*}\right.$ and $\left.\mathrm{OOH}^{*}\right)$ on $\mathrm{Ru}_{x} \mathrm{Ir}_{y} \mathrm{O}_{2}(110)$ were then calculated, which dominate the overall OER activity [29]. After scaling the $\Delta G_{\mathrm{OOH}}$ and $\Delta G_{\mathrm{OH}}$ values (Fig. S1b), we related the calculated OER overpotentials of $\mathrm{Ru}_{x} \mathrm{Ir}_{y} \mathrm{O}_{2}$ (110) to the Ru/Ir ratio in a volcano map (Fig. 1h), and important cases are summarized in Fig. 1i (see detailed data in Table S1 and computational methods in the Supplementary information). As clearly seen, the OER overpotentials of both the $\mathrm{Ru}$ and Ir active sites in $\mathrm{Ru}_{x} \mathrm{Ir}_{y} \mathrm{O}_{2}$ are lower than those in $\mathrm{RuO}_{2}$ and $\mathrm{IrO}_{2}$, respectively, indicating the enhanced OER activity of $\mathrm{Ru}_{x} \mathrm{Ir}_{y} \mathrm{O}_{2}$. The OER overpotentials of the Ir active sites in $\mathrm{Ru}_{x} \mathrm{Ir}_{y} \mathrm{O}_{2}$ (110) model are in the range of $0.50-0.55 \mathrm{~V}$. In comparison, the $\mathrm{Ru}$ active sites display much higher overpotentials in the range of $0.55-0.60 \mathrm{~V}$.

We further investigated the influence of adsorbed oxygen species $\left(\mathrm{H}_{2} \mathrm{O}^{*}, \mathrm{HO}^{*}\right.$ and $\left.\mathrm{O}^{*}\right)$ on the OER overpotentials since these species are important factors in OER energetics [29]. The $\mathrm{Ir}(\mathrm{Ru})$ active sites with adjacent $\mathrm{Ru}-\mathrm{H}_{2} \mathrm{O}, \mathrm{Ru}-\mathrm{OH}$ and $\mathrm{Ru}=\mathrm{O}\left(\mathrm{Ir}-\mathrm{H}_{2} \mathrm{O}, \mathrm{Ir}-\mathrm{OH}\right.$ and $\mathrm{Ir}=\mathrm{O}$, respectively) species in the $\mathrm{Ru}_{x} \mathrm{Ir}_{y} \mathrm{O}_{2}$ (110) model were studied. As shown in Fig. 1i, the $\mathrm{Ru}=\mathrm{O}$ (or similar $\mathrm{Ru}$ $\mathrm{OH})$ species can decrease the adsorption energies of OER intermediates on adjacent Ir active sites and thus enhance the OER activities of adjacent $\mathrm{Ir}$ active sites, compared with the Ir active sites in clean $\mathrm{Ru}_{x} \mathrm{Ir}_{y} \mathrm{O}_{2}$ (110), causing OER overpotential to decrease to a value as low as $\sim 0.45 \mathrm{~V}$ (Fig. S2 and Table S1). Such a low OER overpotential is close to the summit in the volcano map (Fig. 1h). In contrast, the OER activities of Ru active sites are not improved due to the existence of adjacent Ir-OH or $\mathrm{Ir}=\mathrm{O}$ species. The surface phase diagrams (Fig. S3) show that the formation of $\mathrm{Ru}=\mathrm{O}$ species is thermodynamically preferred and prevails over other intermediates $\left(\mathrm{H}_{2} \mathrm{O}^{*}, \mathrm{HO}^{*}\right.$ and $\left.\mathrm{O}^{*}\right)$ adsorbed on either Ru or Ir sites, indicating the existence of $\mathrm{Ru}=\mathrm{O}$ species adjacent to the Ir active centers under actual neutral OER conditions (pH 7).

Inspired by the DFT results, we synthesized $\mathrm{Ru}_{x} \mathrm{Ir}_{y} \mathrm{O}_{2}$ catalysts in an atomically homogenous manner using a sol-gel method [30]. The characteristic peaks in the X-ray diffraction (XRD) pattern of the synthesized $\mathrm{Ru}_{x} \mathrm{Ir}_{y} \mathrm{O}_{2}$ (Fig. S4) can be indexed to $\mathrm{RuO}_{2}$ (JCPDS card No. 431027) and $\mathrm{IrO}_{2}$ (JCPDS card No.15-0870) in the rutile phase. The TEM results (Fig. 2a) show that the $\mathrm{Ru}_{x} \mathrm{Ir}_{y} \mathrm{O}_{2}$ sample features a morphology of nanoparticles with diameter of 3-7 nm. The high-resolution TEM image in 
Fig. $2 \mathrm{~b}$ reveals a high orientation along the [020] projection, and the corresponding fast Fourier transform shows a rutile structure $(P 42 / \mathrm{mnm})$ with high crystallinity, in good agreement with the XRD results. The energy-dispersive spectroscopy (EDS) images and spectrum reveal the atomically homogeneous distribution of $\mathrm{Ru}$ and Ir elements within the $\mathrm{Ru}_{x} \mathrm{Ir}_{y} \mathrm{O}_{2}$ sample (Fig. $2 \mathrm{c}$ and Fig. S5).

The electrochemical measurements of $\mathrm{Ru}_{x} \mathrm{Ir}_{y} \mathrm{O}_{2}$ catalyst were conducted to evaluate its OER activity. As shown in Fig. $2 \mathrm{~d}$ and Fig. S6, the $\mathrm{Ru}_{x} \mathrm{Ir}_{y} \mathrm{O}_{2}$ catalyst on glassy carbon electrodes (GCEs) exhibits a low overpotential of $324 \pm$ $1 \mathrm{mV}$ at $10 \mathrm{~mA} \mathrm{~cm}^{-2}$ (currents are normalized to the projected geometric areas), which is 135 and $431 \mathrm{mV}$ lower than those of benchmark $\mathrm{RuO}_{2}$ and $\mathrm{IrO}_{2}$ catalysts, respectively. The $\mathrm{Ru}_{x} \mathrm{Ir}_{y} \mathrm{O}_{2}$ catalyst with a $\mathrm{Ru} / \mathrm{Ir}$ feed ratio of 4:1 exhibited optimal OER activity among all $\mathrm{Ru}_{x} \mathrm{Ir}_{y} \mathrm{O}_{2}$ catalysts with different $\mathrm{Ru} / \mathrm{Ir}$ feed ratios (Fig. S7). To compare the intrinsic catalytic activities of these catalysts, we analyzed their specific activities with the currents normalized to the electrochemically active surface areas of catalysts (Fig. S8). We confirmed that the $\mathrm{Ru}_{x} \mathrm{Ir}_{y} \mathrm{O}_{2}$ catalyst possessed much higher intrinsic activity than the control catalysts (Table S2). We further evaluated the intrinsic activities of $\mathrm{Ru}_{x} \mathrm{Ir}_{y} \mathrm{O}_{2}$ and control catalysts by determining their TOFs based on the total metal sites and total active sites on GCEs. As shown in Fig. 2e, the $\mathrm{Ru}_{x} \mathrm{Ir}_{y} \mathrm{O}_{2}$ catalyst exhibited the highest TOF of $0.33 \mathrm{~s}^{-1}$, which is 7- and 36-fold higher than those of benchmark $\mathrm{RuO}_{2}$ and $\mathrm{IrO}_{2}$ catalysts, respectively.

To enhance the OER performance of the catalytic electrodes, we improved the electrical conductivities of the substrates by depositing the catalysts on gold-plated nickel foams. The activity trends of catalysts obtained on gold-plated nickel foams remained the same as those observed on GCEs, and the OER performances of catalysts were appreciably enhanced (Fig. S9). The $\mathrm{Ru}_{x} \mathrm{Ir}_{y} \mathrm{O}_{2}$ catalyst on the gold-plated nickel foam electrode achieved $10 \mathrm{~mA} \mathrm{~cm}^{-2}$ at a low overpotential of $260 \pm 2 \mathrm{mV}$ (Table S3, currents are normalized to the projected geometric areas). We evaluated the operating stability of the $\mathrm{Ru}_{x} \mathrm{Ir}_{y} \mathrm{O}_{2}$ catalyst using galvanostatic experiment performed at a constant current density of $10 \mathrm{~mA} \mathrm{~cm}^{-2}$, and no appreciable increases in potential were observed for $500 \mathrm{~h}$ of continuous operation (Fig. S10). The $\mathrm{Ru}_{x} \mathrm{Ir}_{y} \mathrm{O}_{2}$ catalyst in this work exhibited high catalytic activity and
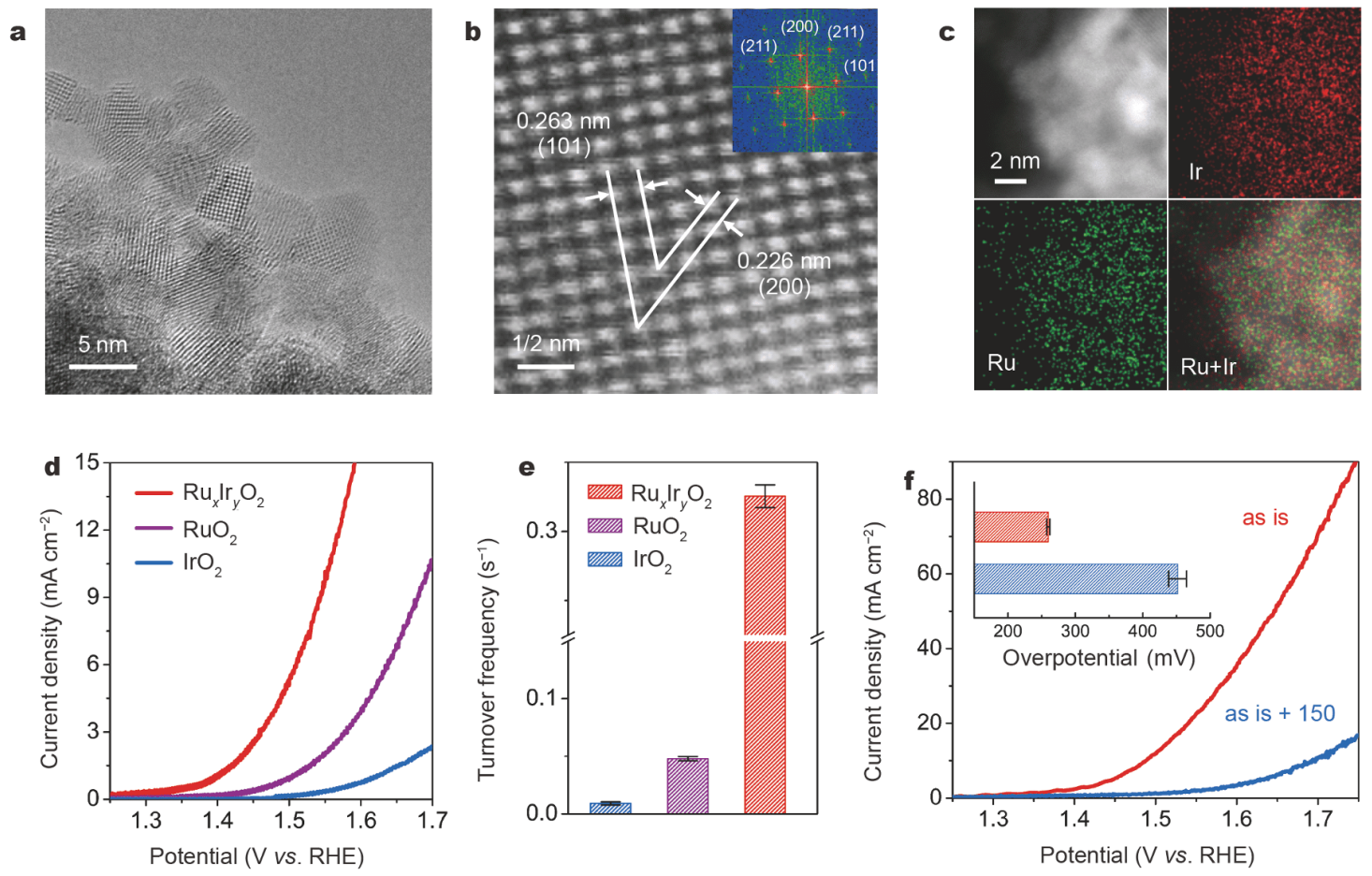

Figure 2 Characterizations and OER performance of $\mathrm{Ru}_{x} \mathrm{Ir}_{y} \mathrm{O}_{2}$ catalysts. (a, b) TEM images of $\mathrm{Ru}_{x} \mathrm{Ir}_{y} \mathrm{O}_{2}$ catalyst. The inset of (b) is the corresponding fast Fourier transform image. (c) EDS elemental mapping images of $\mathrm{Ru}_{x} \mathrm{Ir}_{y} \mathrm{O}_{2}$ catalyst. (d) The LSV curves of $\mathrm{Ru}_{x} \mathrm{Ir}_{y} \mathrm{O}_{2}$ and control catalysts on GCEs at a scan rate of $1 \mathrm{mV} \mathrm{s}^{-1}$ in $\mathrm{CO}_{2}$-saturated $0.5 \mathrm{~mol} \mathrm{~L}^{-1} \mathrm{KHCO}_{3}$ aqueous electrolyte. (e) Comparison of the TOFs of $\mathrm{Ru}_{x} \mathrm{Ir}_{y} \mathrm{O}_{2}$ and control catalysts on GCEs at $1.63 \mathrm{~V}\left(v s\right.$. RHE). (f) The LSV curves of $\mathrm{Ru}_{x} \mathrm{Ir}_{y} \mathrm{O}_{2}$ catalyst on gold-plated nickel foam electrodes before ("as is") and after heating at $150^{\circ} \mathrm{C}$ in vacuum ("as is +150 "). The inset of ( $\mathrm{f}$ ) presents the summarized overpotentials of $\mathrm{Ru}_{x} \mathrm{Ir}_{y} \mathrm{O}_{2}$ electrodes from three independent tests. 
stability in neutral electrolytes. We then applied the $\mathrm{Ru}_{x} \mathrm{Ir}_{y} \mathrm{O}_{2}$ catalyst in an MEC for the synthesis of poly(3hydroxybutyrate) from bioelectrochemical $\mathrm{CO}_{2}$ reduction, and the voltage of the full cell decreased to $1.8 \mathrm{~V}$, which is $200 \mathrm{mV}$ less than the best value reported to date (Fig. S11 and Table S4).

To investigate the influence of adsorbed oxygen species on the OER activity, we controlled the content of adsorbed water molecules and hydroxyl groups on the catalyst surface by heating the catalyst at $150^{\circ} \mathrm{C}$ in vacuum, where these adsorbed species can be removed from the catalyst surface. We first conducted LSV measurements for the $\mathrm{Ru}_{x} \mathrm{Ir}_{y} \mathrm{O}_{2}$ catalysts loaded onto gold-plated nickel foam electrodes without any heating treatment (denoted as the "as is" electrodes). Then these electrodes were heated at $150^{\circ} \mathrm{C}$ in vacuum for $2 \mathrm{~h}$ and further immersed in the electrolyte for $2 \mathrm{~h}$ for sufficient wetting (denoted as the "as is + 150" electrodes) before the LSV measurements. As shown in Fig. $2 \mathrm{f}$ and Fig. S12, substantially increased overpotentials were observed for the "as is + 150" electrodes (the error bars in the inset of Fig. $2 \mathrm{f}$ represent standard deviations from three individual experiments). To eliminate the effect of the substrate, we further carried out similar experiments for $\mathrm{Ru}_{x} \mathrm{Ir}_{y} \mathrm{O}_{2}$ catalysts deposited onto carbon paper electrodes (Fig. S13) and observed a similar increase in the OER overpotentials for the heated electrodes. To exclude the effect of surface hydrophilicity, we measured the contact angles of these electrodes, and almost no variation in contact angles was observed (Fig. S14). These results, taken together, indicate that the adsorbed oxygen species significantly affect the OER activities.

To investigate whether the heating process affects the chemical structures of $\mathrm{Ru}_{x} \mathrm{Ir}_{y} \mathrm{O}_{2}$ catalyst, we first carried out in situ TEM observations on the catalyst before and after heating at $150^{\circ} \mathrm{C}$ in vacuum. The in situ TEM results (Fig. 3a, b) show no changes in the morphology and $d$-spacing of the (110) plane for $\mathrm{Ru}_{x} \mathrm{Ir}_{y} \mathrm{O}_{2}$ catalyst during the in situ heating process. Then, in situ XPS (with and without heating at $150^{\circ} \mathrm{C}$ ) was further conducted to probe the local electronic structure at the surface of $\mathrm{Ru}_{x} \mathrm{I}_{y} \mathrm{O}_{2}$ catalyst. The high-resolution Ir $4 \mathrm{f}$ and $\mathrm{Ru} 3 \mathrm{p}$ spectra (Fig. 3c, d) show no shifts or variations in their characteristic peaks, suggesting the unchanged electronic structures of metal sites at the catalyst surface during in situ heating at $150^{\circ} \mathrm{C}$ in vacuum. The high-resolution O 1s XPS spectra of $\mathrm{Ru}_{x} \mathrm{Ir}_{y} \mathrm{O}_{2}$ catalyst (Fig. 3e) reveal that the contents of adsorbed water molecules and hydroxyl groups appreciably decrease after in situ heating at $150^{\circ} \mathrm{C}$ in vacuum.

To investigate the detailed surface structures of the $\mathrm{Ru}_{x} \mathrm{Ir}_{y} \mathrm{O}_{2}$ catalyst at the atomic scale, we further con-
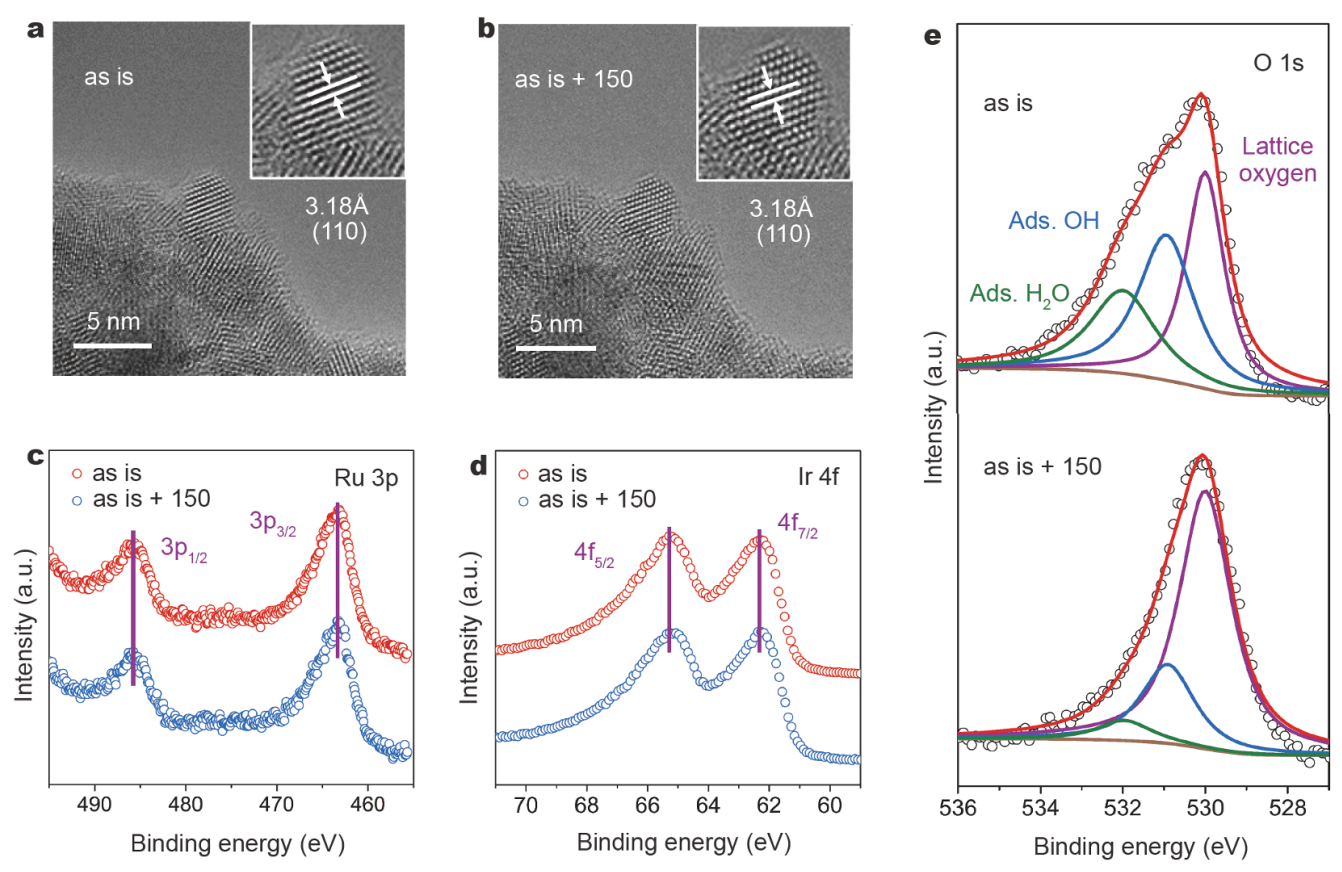

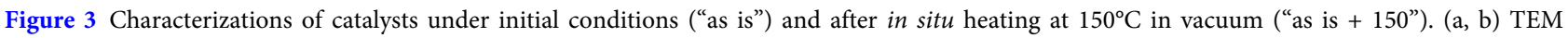
images of $\mathrm{Ru}_{x} \mathrm{Ir}_{y} \mathrm{O}_{2}$ catalyst. (c, d) High-resolution Ru 3p and Ir 4f XPS spectra of $\mathrm{Ru}_{x} \mathrm{Ir}_{y} \mathrm{O}_{2}$, respectively. (e) High-resolution O 1s XPS spectra and the peak fitting results of $\mathrm{Ru}_{x} \mathrm{Ir}_{y} \mathrm{O}_{2}$. 
ducted LEIS measurements with and without heating at $150{ }^{\circ} \mathrm{C}$ in vacuum. As illustrated in Fig. 4a, LEIS can probe the elemental compositions at the topmost atomic layers of $\mathrm{Ru}_{x} \mathrm{Ir}_{y} \mathrm{O}_{2}$ catalyst with ultrahigh surface sensitivity $[31,32]$. The adsorbed oxygen species on the surface $\mathrm{Ru}$ or Ir sites of $\mathrm{Ru}_{x} \mathrm{Ir}_{y} \mathrm{O}_{2}$ catalyst can be quantified by the variations in the $\mathrm{Ru}$ and $\mathrm{Ir}$ signal intensities. As shown in Fig. 4 b, c and Fig. S15, the $\mathrm{Ir} / \mathrm{Ru}$ atomic ratio at the topmost atomic layers of $\mathrm{Ru}_{x} \mathrm{Ir}_{y} \mathrm{O}_{2}$ catalyst decreased from 3.01 to 1.30 after in situ heating at $150^{\circ} \mathrm{C}$ in vacuum, while the bulk $\mathrm{Ir} / \mathrm{Ru}$ atomic ratio barely changed (Fig. S16). Since the compositions and electronic structures of the $\mathrm{Ru}_{x} \mathrm{Ir}_{y} \mathrm{O}_{2}$ catalyst were not changed during in situ heating at $150^{\circ} \mathrm{C}$, the decreased $\mathrm{Ir} / \mathrm{Ru}$ atomic ratio on the topmost layer of the heated $\mathrm{Ru}_{x} \mathrm{Ir}_{y} \mathrm{O}_{2}$ catalyst can be ascribed to the higher amount of oxygen species released from the surface Ru sites than from the surface Ir sites. In conjunction with the DFT studies and electrochemical results, we have confirmed that the higher OER activity of $\mathrm{Ru}_{x} \mathrm{I}_{y} \mathrm{O}_{2}$ before heating compared with $\mathrm{Ru}_{x} \mathrm{Ir}_{y} \mathrm{O}_{2}$ after heating can be attributed to the rich adsorbate-covered $\mathrm{Ru}$ sites adjacent to the Ir active centers on the $\mathrm{Ru}_{x} \mathrm{Ir}_{y} \mathrm{O}_{2}$ surface.

DFT studies were further employed to investigate the origin and mechanism of the enhanced OER activity of $\mathrm{Ru}_{x} \mathrm{Ir}_{y} \mathrm{O}_{2}$ catalyst with adsorbate-covered $\mathrm{Ru}$ sites adjacent to the Ir active centers. As shown in Fig. 4d, the results of the projected densities of states (PDOS) reveal the increased charge of Ru- $\mathrm{d}_{x^{2}-y^{2}}$ after Ru octahedral sites are covered by adsorbed $\mathrm{O}^{*}$ species. Concomitantly, the in-plane $\mathrm{Ru}-\mathrm{O}_{3 \mathrm{c}}$ bonds are elongated due to the cooperative Jahn-Teller distortion associated with the $\mathrm{Ru}$ octahedra after it is covered by adsorbed $\mathrm{O}^{*}$ species. The elongation of the in-plane $\mathrm{Ru}-\mathrm{O}_{3 c}$ bond contracts the adjacent $\mathrm{Ir}-\mathrm{O}_{3 c}$ bond while shortening the in-plane $\mathrm{Ir}-\mathrm{O}_{3 \mathrm{c}}$ bond. On the basis of the bond order conservation principles, the stronger $\mathrm{Ir}-\mathrm{O}_{3 \mathrm{c}}$ bond can weaken the adsorption of OER intermediates on the Ir active site (Fig. S17), especially the adsorption strength of $\mathrm{OOH}^{*}$ intermediates, leading to a decreased overpotential toward OER on $\mathrm{Ru}_{x} \mathrm{Ir}_{y} \mathrm{O}_{2}$.

To further investigate the variations in the $\mathrm{Ru}-\mathrm{O}_{3 \mathrm{c}}$ and $\mathrm{Ir}-\mathrm{O}_{3 \mathrm{c}}$ bonds after the coverage of $\mathrm{Ru}$ octahedral sites by $\mathrm{O}^{*}$ species, projected crystal orbital Hamilton population (pCOHP) calculations were carried out to quantify the interactions between surface $\mathrm{Ru} / \mathrm{Ir}$ and $\mathrm{O}_{3 \mathrm{c}}$ (Fig. 4e). With adsorbed $\mathrm{O}^{*}$ species covering $\mathrm{Ru}$ sites, the filling of the bonding orbital population of $\mathrm{Ru}-\mathrm{O}_{3 \mathrm{c}}\left(\mathrm{Ir}-\mathrm{O}_{3 \mathrm{c}}\right)$ bond deAtomic surfaces

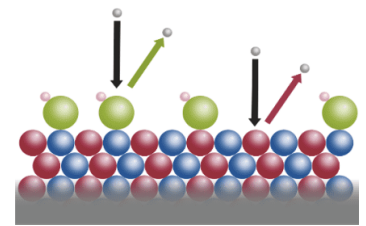

Before heating ("as is")

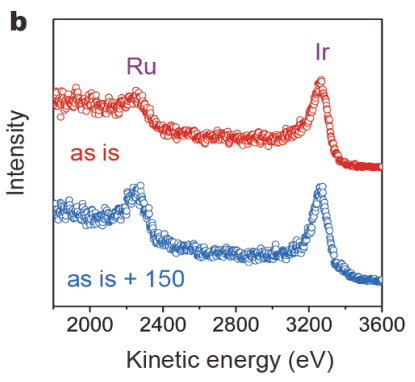

$\mathrm{Ru}^{4+}$ ir. $\mathrm{O} \mathrm{O}^{2} \cdot \mathrm{H} \cdot \mathrm{Ne}$

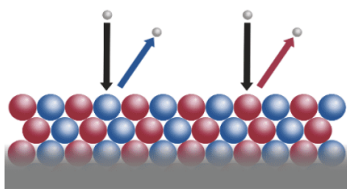

After heating ("as is + 150")

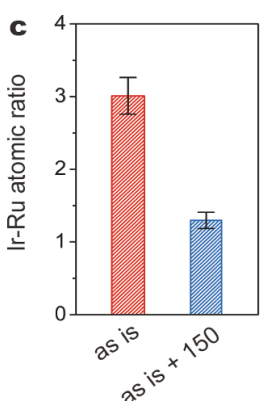

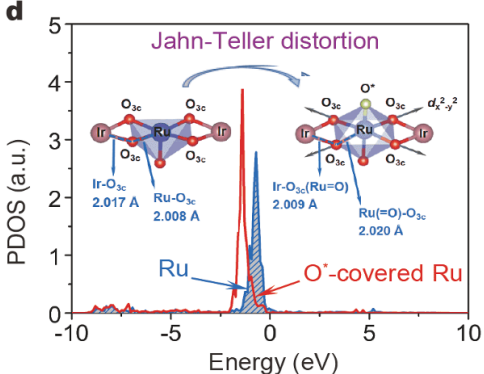

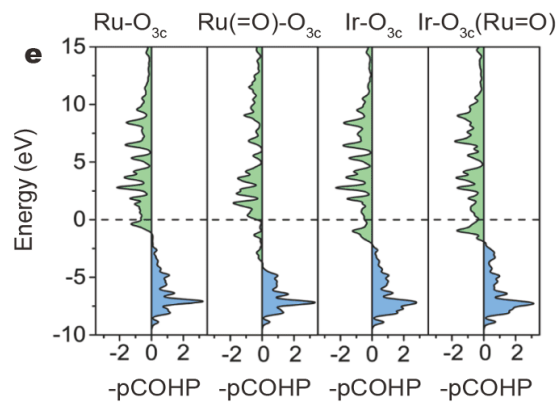

Figure 4 Probing the surface adsorbates and the related study of local structural distortion. (a) Schematic of LEIS on probing the elemental compositions at the topmost surface of $\mathrm{Ru}_{x} \mathrm{Ir}_{y} \mathrm{O}_{2}$ catalyst. (b, c) LEIS spectra and the obtained $\mathrm{Ir} / \mathrm{Ru}$ atomic ratios of $\mathrm{Ru}_{x} \mathrm{Ir} \mathrm{O}_{2} \mathrm{O}_{2}$ catalyst ("as is") and after in situ heating at $150^{\circ} \mathrm{C}$ in vacuum ("as is +150 "), respectively. (d) The PDOS of Ru- $\mathrm{d}_{x^{2}-y^{2}}$ for Ru covered with or without $\mathrm{O}^{*}$, and the elongation of $\mathrm{Ru}-\mathrm{O}_{3 \mathrm{c}}$ bond after $\mathrm{O}^{*}$ covering to shorten the adjacent $\mathrm{Ir}-\mathrm{O}_{3 \mathrm{c}}$ bond due to Jahn-Teller distortion. (e) The pCOHP between $\mathrm{Ru}-\mathrm{O}_{3 \mathrm{c}}$ and Ir-O $\mathrm{O}_{3 \mathrm{c}}$ bonds, with negative (bonding) contributions on the right and positive (antibonding) contributions on the left. 
creases (increases), which corresponds to the decreased (increased, respectively) strength of $\mathrm{Ru}-\mathrm{O}_{3 c}\left(\mathrm{Ir}-\mathrm{O}_{3 c}\right)$ bond, verifying the bond order conservation principles in the $\mathrm{Ru}_{x} \mathrm{Ir}_{y} \mathrm{O}_{2}$ system. Thus, the enhanced OER activity of $\mathrm{Ru}_{x} \mathrm{Ir}_{y} \mathrm{O}_{2}$ can be ascribed to local structural distortion of adjacent $\mathrm{O}^{*}$-covered $\mathrm{Ru}$ octahedra at the catalyst surface and the consequently decreased adsorption energies of OER intermediates on the Ir active site.

\section{CONCLUSIONS}

In summary, by combining in situ XPS, TEM and LEIS studies, we have identified that the electrochemically activated adsorbates on the surface of $\mathrm{Ru}$ sites adjacent to the Ir active centers critically account for the superior neutral OER activity of $\mathrm{Ru}_{x} \mathrm{Ir}_{y} \mathrm{O}_{2}$ catalyst. The obtained $\mathrm{Ru}_{x} \mathrm{Ir}_{y} \mathrm{O}_{2}$ catalyst on the glassy carbon electrode achieves a low overpotential of $324 \mathrm{mV}$ at $10 \mathrm{~mA} \mathrm{~cm}^{-2}$, with 7 -fold and 36-fold improvements in TOF compared with the benchmark $\mathrm{RuO}_{2}$ and $\mathrm{IrO}_{2}$ catalysts, respectively. Further DFT studies indicate that the enhanced OER activity of $\mathrm{Ru}_{x} \mathrm{Ir}_{y} \mathrm{O}_{2}$ arises from Jahn-Teller distortion of adjacent $\mathrm{O}^{*}$-covered $\mathrm{Ru}$ octahedra at the catalyst surface and the consequently decreased adsorption energies of OER intermediates on the Ir active center. In a broader context, this work suggests a general principle for the rational design of heterogeneous catalysts with optimal active surfaces in various catalytic reactions.

\section{Received 16 April 2020; accepted 8 May 2020;}

published online 30 July 2020

1 Seh ZW, Kibsgaard J, Dickens CF, et al. Combining theory and experiment in electrocatalysis: Insights into materials design. Science, 2017, 355: eaad4998

2 Liu C, Colón BC, Ziesack M, et al. Water splitting-biosynthetic system with $\mathrm{CO}_{2}$ reduction efficiencies exceeding photosynthesis. Science, 2016, 352: 1210-1213

3 Xu YT, Ye ZM, Ye JW, et al. Non-3d metal modulation of a cobalt imidazolate framework for excellent electrocatalytic oxygen evolution in neutral media. Angew Chem Int Ed, 2019, 58: 139-143

4 Anantharaj S, Aravindan V. Developments and perspectives in 3d transition-metal-based electrocatalysts for neutral and near-neutral water electrolysis. Adv Energy Mater, 2020, 10: 1902666

5 Xie L, Zhang R, Cui L, et al. High-performance electrolytic oxygen evolution in neutral media catalyzed by a cobalt phosphate nanoarray. Angew Chem Int Ed, 2017, 56: 1064-1068

6 Zhang K, Guo W, Liang Z, et al. Metal-organic framework based nanomaterials for electrocatalytic oxygen redox reaction. Sci China Chem, 2019, 62: 417-429

7 Yang $\mathrm{H}$, Wang C, Zhang $\mathrm{Y}$, et al. Green synthesis of NiFe LDH/Ni foam at room temperature for highly efficient electrocatalytic oxygen evolution reaction. Sci China Mater, 2019, 62: 681-689

8 Zhang S, Lv F, Zhang X, et al. Ni@RuM (M=Ni or Co) core@shell nanocrystals with high mass activity for overall water-splitting catalysis. Sci China Mater, 2019, 62: 1868-1876

9 Grimaud A, Demortière A, Saubanère $M$, et al. Activation of surface oxygen sites on an iridium-based model catalyst for the oxygen evolution reaction. Nat Energy, 2017, 2: 16189

10 Chen J, Cui P, Zhao G, et al. Low-coordinate iridium oxide confined on graphitic carbon nitride for highly efficient oxygen evolution. Angew Chem Int Ed, 2019, 58: 12540-12544

11 Zhang T, Liao SA, Dai LX, et al. Ir-Pd nanoalloys with enhanced surface-microstructure-sensitive catalytic activity for oxygen evolution reaction in acidic and alkaline media. Sci China Mater, 2018, 61: 926-938

12 Chen $\mathrm{Z}$, Zhao $\mathrm{H}$, Zhang J, et al. IrNi nanoparticle-decorated flower-shaped $\mathrm{NiCo}_{2} \mathrm{O}_{4}$ nanostructures: Controllable synthesis and enhanced electrochemical activity for oxygen evolution reaction. Sci China Mater, 2017, 60: 119-130

13 Chandra D, Takama D, Masaki T, et al. Highly efficient electrocatalysis and mechanistic investigation of intermediate $\operatorname{IrO}_{x}(\mathrm{OH})_{y}$ nanoparticle films for water oxidation. ACS Catal, 2016, 6: 39463954

14 Li T, Kasian O, Cherevko S, et al. Atomic-scale insights into surface species of electrocatalysts in three dimensions. Nat Catal, 2018, 1: 300-305

15 Massué C, Pfeifer V, van Gastel M, et al. Reactive electrophilic $\mathrm{O}^{\mathrm{I}}$ species evidenced in high-performance iridium oxohydroxide water oxidation electrocatalysts. ChemSusChem, 2017, 10: 47864798

16 Saeed KH, Forster M, Li JF, et al. Water oxidation intermediates on iridium oxide electrodes probed by in situ electrochemical SHINERS. Chem Commun, 2020, 56: 1129-1132

17 Abbott DF, Lebedev D, Waltar K, et al. Iridium oxide for the oxygen evolution reaction: Correlation between particle size, morphology, and the surface hydroxo layer from operando XAS. Chem Mater, 2016, 28: 6591-6604

$18 \mathrm{Xu} \mathrm{K}$, Cheng H, Liu L, et al. Promoting active species generation by electrochemical activation in alkaline media for efficient electrocatalytic oxygen evolution in neutral media. Nano Lett, 2017, 17: $578-583$

19 Willinger E, Massué C, Schlögl R, et al. Identifying key structural features of $\mathrm{IrO}_{x}$ water splitting catalysts. J Am Chem Soc, 2017, 139: 12093-12101

20 Wang $\mathrm{N}$, Cao Z, Zheng X, et al. Hydration-effect-promoting Ni-Fe oxyhydroxide catalysts for neutral water oxidation. Adv Mater, 2020, 32: 1906806

21 Sun W, Song Y, Gong XQ, et al. An efficiently tuned d-orbital occupation of $\mathrm{IrO}_{2}$ by doping with $\mathrm{Cu}$ for enhancing the oxygen evolution reaction activity. Chem Sci, 2015, 6: 4993-4999

22 Nong HN, Reier T, Oh HS, et al. A unique oxygen ligand environment facilitates water oxidation in hole-doped $\mathrm{IrNiO}_{x}$ coreshell electrocatalysts. Nat Catal, 2018, 1: 841-851

23 Gao J, Xu CQ, Hung SF, et al. Breaking long-range order in iridium oxide by alkali ion for efficient water oxidation. J Am Chem Soc, 2019, 141: 3014-3023

24 Zhang J, Chen Z, Liu C, et al. Hierarchical iridium-based multimetallic alloy with double-core-shell architecture for efficient overall water splitting. Sci China Mater, 2020, 63: 249-257

25 Shustorovich E. Coverage effects under atomic chemisorption: Morse-potential modeling based on bond-order conservation. Surf Sci, 1985, 163: L645-L654

26 Man IC, Su H, Calle-Vallejo F, et al. Universality in oxygen evolution electrocatalysis on oxide surfaces. ChemCatChem, 2011, 3: 
1159-1165

27 Li H, Opgenorth PH, Wernick DG, et al. Integrated electromicrobial conversion of $\mathrm{CO}_{2}$ to higher alcohols. Science, 2012, 335: 1596

28 Giddings CGS, Nevin KP, Woodward T, et al. Simplifying microbial electrosynthesis reactor design. Front Microbiol, 2015, 6: 468

29 Fang YH, Liu ZP. Mechanism and Tafel lines of electro-oxidation of water to oxygen on $\mathrm{RuO}_{2}$ (110). J Am Chem Soc, 2010, 132: 18214-18222

30 Zhang B, Zheng X, Voznyy O, et al. Homogeneously dispersed multimetal oxygen-evolving catalysts. Science, 2016, 352: 333-337

31 Danilovic N, Subbaraman R, Chang KC, et al. Using surface segregation to design stable $\mathrm{Ru}-\mathrm{Ir}$ oxides for the oxygen evolution reaction in acidic environments. Angew Chem Int Ed, 2014, 53: 14016-14021

32 Roy C, Sebok B, Scott SB, et al. Impact of nanoparticle size and lattice oxygen on water oxidation on $\mathrm{NiFeO}_{x} \mathrm{H}_{y}$. Nat Catal, 2018, 1: 820-829

Acknowledgements This work was supported by the Ministry of Science and Technology (2016YFA0203302), the National Natural Science Foundation of China (21875042, 21634003, 51573027 and 11227902), Science and Technology Commission of Shanghai Municipality (16JC1400702 and 18QA1400800), Shanghai Municipal Education Commission (2017-01-07-00-07-E00062), Yanchang Petroleum Group, and the Program for Professor of Special Appointment (Eastern Scholar) at Shanghai Institutions of Higher Learning. This work also benefited from 1W1B beamline at Beijing Synchrotron Radiation Facility (BSRF) and BL02B01 beamline at Shanghai Synchrotron Radiation facility (SSRF).

Author contributions Peng $\mathrm{H}$, Zhang B and Wang $\mathrm{H}$ supervised the project; Yuan $\mathrm{H}$ and Wang $\mathrm{H}$ performed the DFT simulations; Zhang $\mathrm{L}$ and Wang $\mathrm{L}$ carried out the synthesis of catalysts and electrochemical measurements; Zhang $\mathrm{H}$ and Zang $\mathrm{Y}$ performand the in situ XPS experiments; Tian $\mathrm{Y}$ and Song $\mathrm{H}$ performed the microbial electrolysis experiments. All authors discussed the results and assisted during the manuscript preparation.

Conflict of interest The authors declare that they have no conflict of interest.

Supplementary Information Detailed experimental information and supporting data are available in the online version of the paper.

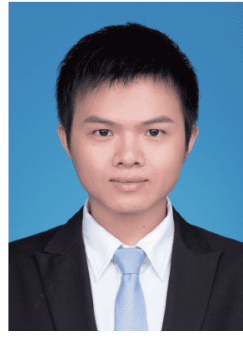

Longsheng Zhang received his $\mathrm{BE}$ degree in material forming and control engineering from South China University of Technology in 2013, and MSc degree in macromolecular chemistry and physics from Fudan University in 2016. He is a $\mathrm{PhD}$ candidate in the Laboratory of Advanced Materials at Fudan University. His research focuses on electrochemistry, energy conversion and storage.

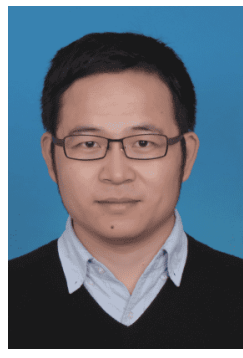

Bo Zhang received his BE in applied physics from Northwestern Polytechnical University in 2006, and $\mathrm{PhD}$ in chemical engineering and technology from East China University of Science and Technology in 2011. He then worked at East China University of Science and Technology from 2011 to 2015, and at University of Toronto from 2015 to 2017. He is currently a full professor in the Department of Macromolecular Science at Fudan University. His research focuses on electrochemistry, energy conversion and storage.

\section{电化学活化吸附物对中性析氧反应的影响}

张龙生 ${ }^{1 \dagger}$, 袁海洋 ${ }^{2 \dagger}$, 王丽平 ${ }^{1}$, 章辉 ${ }^{3}$, 藏易静 ${ }^{3}$, 田瑶, 温蕴周 ${ }^{1}$,

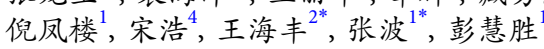

摘要 高效中性析氧催化剂在微生物电解池领域起着至关重要的 作用. 但是, 目前中性析氧催化剂的过电位仍较高, 其反应动力学极 为缓慢. 在本工作中, 我们成功设计并制备了一种高效 $\mathrm{Ru}_{x} \mathrm{Ir}_{y} \mathrm{O}_{2}$ 催 化剂, 它兼具高析氧活性和高稳定性, 其本征活性分别是商业 $\mathrm{RuO}_{2}$ 和 $\mathrm{IrO}_{2}$ 催化剂的7倍和36倍. 我们进一步通过原位透射电子显微 镜、光电子能谱和低能离子散射谱测试研究了 $\mathrm{Ru}_{x} \mathrm{Ir}_{y} \mathrm{O}_{2}$ 的表面吸 附物对其催化活性的影响. 结合密度泛函理论计算和实验结果, 发 现 $\mathrm{Ru}_{x} \mathrm{Ir}_{y} \mathrm{O}_{2}$ 催化剂中 $\mathrm{Ru}$ 位点被 $\mathrm{O}^{*}$ 吸附物覆盖可提高其相邻 Ir 位点 的催化活性. 因为Jahn-Teller效应, 当Ru-O键被削弱时, 其相邻的 $\mathrm{Ir}-\mathrm{O}$ 键会增强, 从而减弱 Ir位点对反应中间产物的吸附, 最终提高 $\mathrm{Ru}_{x} \mathrm{Ir}_{y} \mathrm{O}_{2}$ 催化剂的析氧活性. 